\title{
PRESENTACIÓN
}

\section{México y Norteamérica hoy}

DOI: $10.32870 /$ mycp.v1i1.383

\author{
Arturo Santa Cruz \\ José Jaime López Jiménez*
}

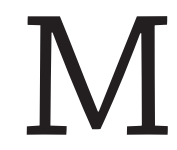

éxico es parte de Norteamérica. Esto no implica por supuesto el falso dilema de elegir entre América Latina y América del Norte. México pertenece a ambas regiones. Pero, para bien o para mal, la segunda es no sólo el motor de nuestra economía, sino también el principal destino - y no sólo turístico- de los mexicanos. El 83\% de nuestras exportaciones y $51 \%$ de nuestras importaciones van a y vienen de la región. De manera similar, más de 11 millones de turistas (88\% del turismo que recibe México) provienen de los dos socios regionales, mismos que visitan más de seis millones de mexicanos anualmente, y en los que viven más de 11 millones de compatriotas. La intensidad de la relación económica y social con los otros dos países de la región no tiene, pues, parangón.

Sin embargo, la concepción de México como un país norteamericano tiene apenas dos décadas (a pesar de que el primer nombre oficial de nuestro país fue el de "América Septentrional"). Nació a inicios de los años noventa —luego del proceso de "integración silenciosa" de la década anterior - con la propuesta mexicana de negociar un tratado de libre comercio con Estados Unidos, a la que después se sumó Canadá. Es desde entonces que se empieza a hablar de una América del Norte conformada por tres países. Como resultado de la nueva sociedad, el comercio y la inversión crecieron sostenidamente durante los primeros años de su entrada en vigor.

Profesores investigadores del Departamento de Estudios del Pacífico, del Centro Universitario de Ciencias Sociales y Humanidades de la Universidad de Guadalajara, y miembros del SNI. 
Así, las exportaciones mexicanas hacia Canadá crecieron en $127 \%$ entre 1993 y el año 2000, mientras que las importaciones de ese país lo hicieron a una tasa de $241 \%$ en ese mismo periodo. Para el año 2002 México era ya el cuarto socio comercial canadiense y el principal en América Latina. En lo que respecta al vecino del norte, las exportaciones mexicanas hacia ese país crecieron en $241 \%$ entre 1993 y el año 2000, mientras que las importaciones lo hicieron a una tasa de $181 \%$ en ese mismo periodo. En el año 2000 México ocupaba ya el segundo lugar como socio comercial estadounidense. De manera similar, el flujo promedio anual de inversión canadiense fue de 418 millones de dólares de 1993 al año 2000 y el estadounidense de 6,594, representando entre los dos países $75 \%$ del total anual promedio para el mismo periodo. Además, los lazos políticos y sociales se fortalecieron marcadamente desde la entrada en vigor del Tratado de Libre Comercio de América del Norte (TLCAN), como se ha podido ver en los acercamientos diplomáticos, culturales y sociales entre los tres países.

Sin embargo, esta joven América del Norte está ya en problemas. Otros procesos paralelos en el ámbito internacional, tales como la globalización y la regionalización, pero especialmente el ascenso de China en la economía internacional, han contribuido a que Norteamérica pierda peso relativo en la economía política mundial. Así, el comercio intrarregional ha venido decreciendo desde el año 2000, pasando de 46 a $41 \%$ del total de comercio en 2006. La tasa de crecimiento del comercio tanto con Canadá como con Estados Unidos disminuyó considerablemente en el primer lustro de este siglo respecto a la década anterior (en aproximadamente $25 \%$ para las exportaciones y $75 \%$ para las importaciones hacia y de Canadá; ya que con el vecino del norte la tasa de decrecimiento para los mismos periodos en lo que respecta a las exportaciones fue superior a $50 \%$, si bien la tasa de cambio del crecimiento de las importaciones provenientes de ese país fue positiva, de alrededor de 60\%).

El gobierno del presidente Ernesto Zedillo no llevó a cabo iniciativas de alta envergadura en términos de institucionalización de la relación bilateral o trilateral - con excepción del Grupo de Contacto de Alto Nivel—, limitándose a dar seguimiento a la nueva relación económica y política con los otros dos países de la región. Fue pues el gobierno de Vicente Fox el que propuso a los dos socios comerciales una ambiciosa agenda de consolidación regional —el llamado TLCAN — o Nafta-Plus. Por diversas razones (incluyendo el marcado desinterés por parte de Ottawa y la concentración de Washington 
en su seguridad luego de los atentados terroristas de septiembre de 2001) la propuesta no prosperó.

De manera por demás tímida y careciendo de una "gran idea", el proyecto integracionista cristalizó en marzo de 2005 en la Asociación para la Seguridad y la Prosperidad en América del Norte (ASPAN) — un caso claro de avance a partir de lo que entonces era políticamente viable, no de lo deseable, como diplomáticos de los tres países reconocerían a la postre-. El objetivo del nuevo mecanismo era doble: por una parte, plantear una agenda de seguridad para enfrentar de manera coordinada problemas comunes a los tres países. Por otra, una agenda de prosperidad para promover el crecimiento y las oportunidades económicas. Aunque exitoso en el contexto de sus limitadas ambiciones, el mecanismo dejó de funcionar en 2009.

Sin duda el legado más importante del ASPAN es el mecanismo de Cumbres de Líderes de América del Norte. La importancia de este componente es que eleva el nivel de la agenda norteamericana en las tres capitales de la región al reunir a los tres mandatarios una vez al año, siendo así la única instancia que puede hacer pensar en la conducción política trilateral de la problemática de la región. Sin embargo, la permanencia del mecanismo no está del todo asegurada. Los tres jefes de gobierno de la región se han reunido en sólo cuatro ocasiones: 2006 en Cancún, 2007 en Montebello, 2008 en Nueva Orleans y 2009 en Guadalajara; en 2010 no hubo cumbre y en 2011 sólo el presidente estadounidense y el primer ministro canadiense se reunieron en Hawai (pues el presidente Calderón tuvo que cancelar su asistencia debido al deceso de su Secretario de Gobernación, Francisco Blake Mora).

Lo anterior refleja de alguna manera el frágil estado del proceso de regionalización en América del Norte. Por una parte, como ya se sugirió, Washington se concentró en la agenda de seguridad con sus vecinos, a expensas de la miríada de temas que atañen a la región. Por otra, los dos socios menores, Canadá y México, volvieron no sólo a privilegiar su relación con el vecino compartido, sino prácticamente a abandonar el proyecto de integración regional. Por el lado canadiense, el temor a lo que varios de sus altos funcionarios llamaban la "mexicanización" de la agenda con Washington, es decir, que los temas que a su país más preocupan se vieran desplazados y/o "contaminados" por los que conciernen a la relación bilateral de sus vecinos del sur, y como consecuencia que Ottawa perdiera su "relación especial" con Washington, llevaron a ese país a mantener cierta distancia respecto al enfoque trilateral de la agenda regional. 
Por el lado mexicano, durante el gobierno de Felipe Calderón la naciente agenda trilateral fue sustituida no sólo por la relación con el vecino del norte; todavía más, dentro de ésta se privilegió el tema de la seguridad - a expensas de los muchos otros expedientes de la agenda bilateral-. La Iniciativa Mérida —independientemente de sus logros en muchos sentidos — es paradigmática en este sentido.

Hay que reconocer, sin embargo, que tal vez hubo motivos para hacer a un lado el ambicioso proyecto trilateral. Ciertamente existen temas, por ejemplo el de la migración, o el de las cuestiones de seguridad relacionadas con el narcotráfico, que es mejor tratar fundamentalmente de manera bilateral entre Tlatelolco y Washington; así como existen otros, tales como el paso por el Ártico o cuestiones relacionadas con la interoperabilidad de fuerzas militares, que conciernen fundamentalmente a Ottawa y Washington. Canadá y México, por su parte, pueden estar más interesados que Washington en promover esquemas multilaterales de acción política en áreas tales como la gobernanza internacional o el cambio climático. Así pues, al pensar en la política que México debe seguir hacia la región en los próximos años, se debe ubicar al trilateralismo en su justa dimensión.

Lo que México necesita es consolidar las dos relaciones bilaterales con sus vecinos del norte al mismo tiempo que, con base en una política ambiciosa pero realista, se pone en práctica una política hacia la región en su conjunto que contribuya a su consolidación institucional. Así, en relación con la agenda México-Canadá, lo conveniente para la próxima administración será, en primer término, fortalecer la relación política con el fin de relanzar tanto la agenda bilateral como potenciales iniciativas conjuntas en el ámbito multilateral. Así, por ejemplo, la remoción del requerimiento de visa para turistas mexicanos que visitan aquel país debe ser una prioridad, por lo simbólico de la medida. Más sustancialmente, es importante que la inversión canadiense crezca y se diversifique (actualmente se encuentra fuertemente concentrada en los sectores bancario y minero) y que el comercio bilateral recobre su dinamismo. Buena parte de las medidas específicas a concretar en este sentido están contenidas en el Plan de Acción Conjunto México-Canadá 2010-2012, el cual, de manera desafortunada, prácticamente no se ha llevado a cabo.

En lo referente a la relación con Estados Unidos, lo más importante es construir mecanismos eficaces para tratar la tan rica agenda bilateral, así como relanzar los ya existentes y que han demostrado su utilidad en el pasado, como por ejemplo la Comisión Binacional. Los mecanismos a utilizar deben 
responder claramente a objetivos precisos, identificados de manera bilateral al más alto nivel. No se trata de crear una multitud de instancias, sino tan sólo unas pocas que puedan concentrar la atención de los principales tomadores de decisiones y que funcionen adecuadamente. Temas como facilitación comercial, infraestructura fronteriza, medio ambiente, migración, seguridad deben figurar en los primeros lugares de la agenda bilateral del próximo gobierno. Sólo trabajando conjunta, cotidiana y productivamente se podrá no sólo vencer el desinterés que nuestro vecino del norte muestra en temas de cardinal importancia para nuestro país, sino también construir una relación políticamente más equilibrada y respetuosa, una que evite la repetición de incidentes lamentables recientes en la relación bilateral, como el Operativo Rápido y Furioso en 2009-2010.

Finalmente, en lo concerniente a Norteamérica como región, ciertamente existen intereses comunes que deben ser abordados de manera trilateral. Un ejemplo fehaciente de cooperación tripartita exitosa se dio en el contexto de la pandemia ocasionada por el virus AH1N1 en 2009. Con base en mecanismos en la materia acordados en ASPAN, los tres países cooperaron ejemplarmente para atacar el problema, y ni Canadá ni Estados Unidos cerraron sus fronteras a los mexicanos durante dicha crisis. Pero incluso en áreas como seguridad o medio ambiente puede practicarse una diplomacia trilateral acotada, consciente de los límites del tratamiento regional a dichas temáticas. Es pues fundamental dar continuidad anual a las Cumbres de Líderes de América del Norte. El próximo gobierno de México debe evitar el miedo a la toma de posición pública respecto a la pertenencia de nuestro país a América del Norte - México es parte de ella, asumámoslo y actuemos en consecuencia.

Con el objeto de incorporar a México y la Cuenca del Pacífico (MyCP) a la nueva tendencia global de publicaciones en línea, el Consejo Editorial ha acordado publicar $\boldsymbol{M y C P}$ a partir de 2012 en versión electrónica, además de su versión impresa. El nuevo formato permitirá que $\boldsymbol{M y C P}$ se acerque a un universo más amplio de lectores y colaboradores, constituyéndose de manera más efectiva en un referente para quienes buscan una perspectiva académica integral de la dinámica de Asia-Pacífico.

El presente número de la revista México y la Cuenca del Pacífico incluye cuatro artículos en su sección de "Análisis" y una reseña. Tomohiro Machikita, Truong Thi Chi Binh y Yasushi Ueki, en el primer trabajo, a partir del análisis de los resultados de una encuesta realizada a firmas manufactureras filipinas y vietnamitas, buscan identificar las fuentes así como los efectos de la transfe- 
rencia de tecnología en un distrito industrial consolidado en Filipinas y en una aglomeración de rápido crecimiento en Hanoi, Vietnam. Los autores resaltan entre los efectos significativos de dicha transferencia, mediante el intercambio de ingenieros entre clientes y proveedores, una mejora importante en los procesos fundamentales en las firmas en Hanoi. Asimismo, argumentan que el intercambio de ingenieros influye positivamente de manera significativa en la producción y en el control de calidad de productos nuevos introducidos por las firmas en Calabarzon, Filipinas. Concluyen que la diferencia en los efectos del intercambio de ingenieros entre los dos distritos industriales tiene que ver con la diferencia en los grados de desarrollo industrial relativos de los dos países.

Daniel Ricardo Lemus, por su parte, analiza la relación entre el discurso sobre la cooperación internacional y la construcción de la imagen de la Gran China, con base en el discurso de la élite burocrática china en el marco del Foro sobre Cooperación China-África. El trabajo se sustenta en el enfoque del constructivismo para explicar la forma en que las identidades construidas socialmente y las acciones asumidas por los Estados, condicionadas en parte por dichas identidades, interactúan mutuamente y moldean el escenario internacional. Con base en lo anterior, el autor expone que además de las estructuras materiales que ubican a China como una potencia en ascenso, en forma paralela este país ha estado moldeando la imagen de un Estado que corresponda con su creciente poderío. De esta forma, de acuerdo con el mismo autor, China construye una identidad en la que se representa como un Estado responsable en el escenario internacional, que apuesta por un orden multilateral y que al mismo tiempo se interesa por el desarrollo de los países africanos, desde una óptica distinta. El autor concluye que China podría estar diseñando un modelo alterno de cooperación internacional para el desarrollo, que proyecta al gigante asiático como una alternativa diferente hacia el desarrollo en la que los países africanos se pueden apoyar y seguir.

Eduardo Tzili, en su trabajo sobre China y la provisión de bienes públicos globales, expone que el resurgimiento del gigante asiático como potencia global ha provocado escepticismo y a la vez tranquilidad en el escenario internacional. Por un lado, la posibilidad de que China llegue a disputar la hegemonía a Estados Unidos por medio de la fuerza y, por otro, la posibilidad de convertirse en un contrapeso importante para Occidente. Recurriendo a la teoría de la estabilidad hegemónica, el autor busca identificar una potencial hegemonía de China a través de su capacidad de proveer los llamados bienes 
públicos globales, esto es, si la capacidad de abastecimiento de China de dichos bienes podría constituir o no un rasgo hegemónico. Para ello, el autor analiza el papel de China en la crisis financiera asiática de 1997-1998 y la reciente crisis financiera global de 2008-2010, centrándose particularmente en la participación de China en el suministro de bienes públicos globales.

Finalmente, Héctor Palacios, desde una perspectiva histórica, analiza las relaciones de Japón y México y la inmigración japonesa durante el Porfiriato. El autor encuentra cierto paralelismo entre los sucesos políticos y militares ocurridos en Japón y México a mediados del siglo XIX, sucesos que en cierta forma respondían a las presiones externas y a las condiciones internas que ambos experimentaban, los cuales tenían como meta el convertirse en Estados-nación modernos capaces de enrolarse en el orden internacional. En ese contexto, de acuerdo con el autor, es como las dos naciones firmaron el Tratado de Amistad, Navegación y Comercio, lo que abrió la puerta al flujo migratorio de japoneses a través de puertos mexicanos desde finales del siglo XIX.

Expresamos nuestro sincero agradecimiento a todos nuestros colaboradores por el apoyo brindado a México y la Cuenca del Pacífico, a los miembros tanto del Consejo Editorial como del Comité Editorial por su generosa e invaluable labor para preservar la calidad de la revista, y al Centro Universitario de Ciencias Sociales y Humanidades de la Universidad de Guadalajara por el apoyo para la publicación de la misma. mig 
WON

EE

THE ASIA-PACIFIC, REGIONALISM AND THE GLOBAL SYSTEM

\section{EDITED BY \\ CHRISTOPHER M. DENT AND JÖRN DOSCH}

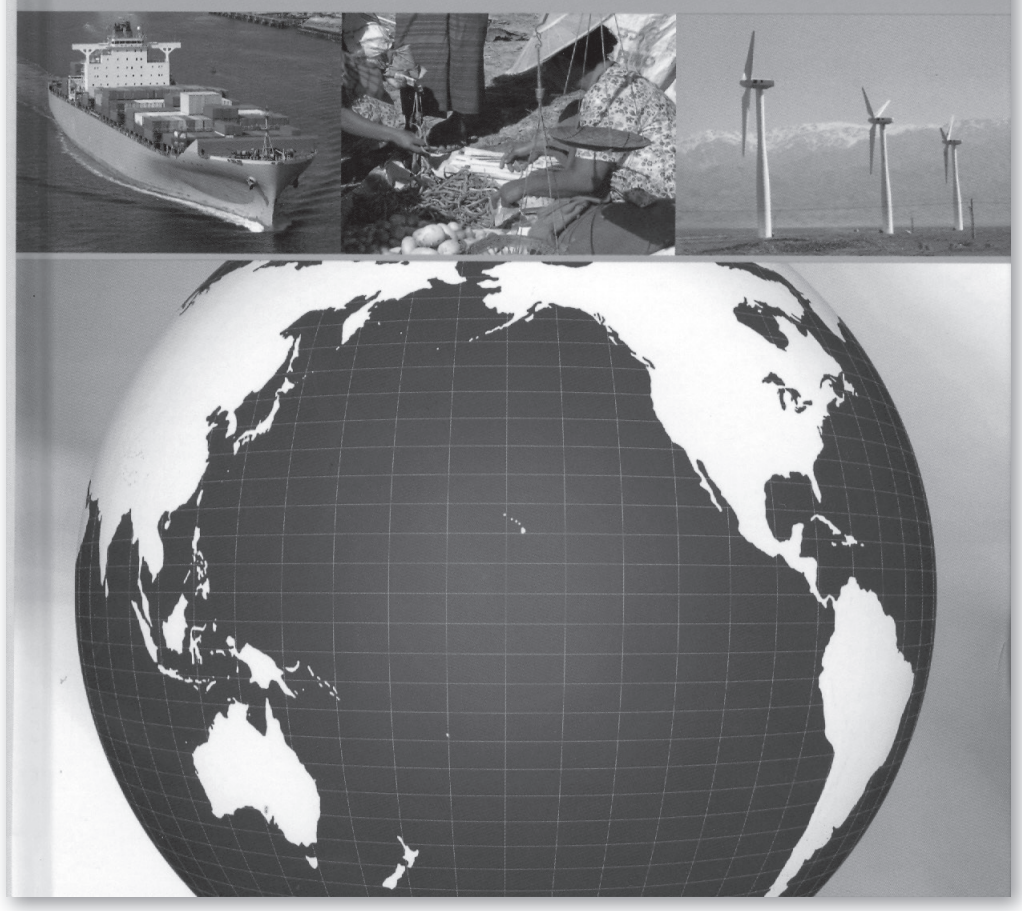

